\title{
Suppressor Device
}

National Cancer Institute

\section{Source}

National Cancer Institute. Suppressor Device. NCI Thesaurus. Code C50198.

An electrical device designed to reduce or eliminate unwanted currents. 